\title{
Effect of the Pressure and the Density on the Air Fuel Ratio for Thermal Power Plant
}

\author{
Prosper Ndizihiwe $^{1}$, Dr. Burnet Mkandawire ${ }^{2}$, Dr. Venant Kayibanda ${ }^{3}$ \\ ${ }^{1}$ University of Rwanda, College of Sciences and Technology, Rwanda \\ ${ }^{2}$ University of Malawi, Faculty of Engineering, Malawi \\ ${ }^{3}$ University of Rwanda, College of Sciences and Technology, Rwanda
}

\begin{abstract}
The control of the air-fuel ratio (AFR) is critical for the efficiency of the combustion. This is for achieving the better performance of the plant and result in high output energy. Different parameters influence AFR. This paper models AFR as a function of the inlet temperature, density, and pressure. Formulated models have been checked using recorded data from the site. The results show that the AFR increases by 1.5 units as the pressures of the gas increase by 0.6 bars but when it reaches 2.9 bar, AFR starts to decrease, $0.9 \%$ of the increase of the density leads to the decrease of the AFR of 0.4 in average. $3.5^{\circ} \mathrm{C}$ rise of inlet temperature lift the AFR by 0.2; however, it starts to decrease when the temperature reaches $78^{\circ} \mathrm{C}$.
\end{abstract}

Key works: Air Fuel Ratio, Pressure, Temperature, Density, Combustion.

\section{INTRODUCTION}

The combustion within the boiler burns fuel to create heat energy. The burning of fuel is the reaction of fuel with oxygen present in the air. The amount of fuel that can be burnt is limited by the oxygen in the cylinder [1]. Once all the fuel is not burnt at all, some of it stays in the boiler and other quantity of flue gases goes to the atmosphere. This is the loss that causes small efficiency at some time abuses our environment [2]. It is therefore important to maintain AFR at optimum.

By definition, AFR is the fraction of air mass and the fuel mass. Different researchers like A. Marjanovi et al [3], S. Mcallister [4], H. Audai H and N. Jamal [5] among others have been conducted considering the quantification of the air composition and the fuel composition. This is very important however other variables can alter the behavior of the AFR.

M.C. Janus et al [6],[7], Hadyan Fahad [8], Luo Chao et al [9], Liang et al [10], have all searched on the contribution of the temperature, the density, and the pressure and found that there are their influences on the combustion as well as the AFR, However, they didn't estimate the how much they contribute. It is important to know how much any of its change varies the AFR at any kid of the fuel to achieve better combustion for efficient boiler performance.

In this research work the AFR is modeled as a function of the inlet temperature of the fuel and the outlet density of the gases, then as a function of the pressure at the entry of the air.

Section 2, demonstrate the model of the AFR with the variation of the density and the temperature and validate it using experimental data from the field. In section 3, the author demonstrates the model of the AFR with the change of the pressure and experimental result are presented. In section 4 there is a conclusion, recommendations as well as proposed future work.

\section{CONSIDERATION OF THE DENSITY AND THE TEMPERATURE}

The AFR is modeled by the quotient of the model of the air and fuel. To do that let consider the entry and exit of the particles within the boiler and utilize the principle of energy and mass conservation. Analysis of the mass entry and exit in the furnace on Figure 1 helps for that analysis 


\subsection{Model formulation}

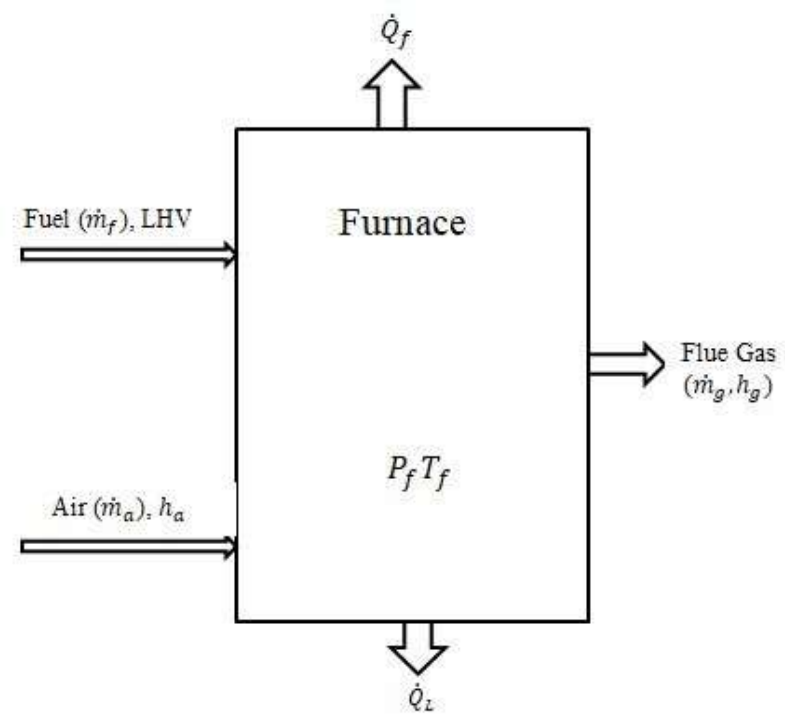

Figure 1: Entry and Exit of the furnace

Figure 1shows that the inputs which vary with time are the fuel and the air. The output is the gas pressure. The general form of mass conservation stated by the law of thermodynamics[11], [12] says that

$$
\begin{gathered}
\frac{d}{d t} m(t)=\dot{m}_{\text {in }}(t)-\dot{m}_{\text {out }}(t) \\
\frac{d}{d t} U(t)=\dot{H}_{\text {in }}(t)-\dot{H}_{\text {out }}(t)+\dot{Q}(t)
\end{gathered}
$$

$U(t)$ : the internal energy, $\dot{H}$ : enthalpy flow and $\dot{Q}(t)$ : the heat, under the assumption that there is no heat and mass transfer in the walls as well as a change in kinetic and potential energies during the flow.

Deploying equation (Error! Reference source not found.) considering or both energy and mass, we can have the following equations [13]:

$$
V_{f}\left(\frac{d\left(\rho_{g} \cdot h_{g}\right)}{d t}\right)=\dot{m}_{a} h_{a}+\dot{m}_{f b} L H V-\dot{m}_{g} h_{g}-Q_{f}-Q_{L}
$$

$Q_{f}:$ the heat transfer by radiation $Q_{L}:$ the heat transfer by furnace wall, $L H V:$ The lower heating value of the fuel, $\dot{m}_{f b}$ is the burned fuel mass flow rate, $V_{f}$ is the furnace volume, $\rho$ is the density and $h$ is the enthalpy.

$$
\begin{gathered}
\dot{Q}_{f}=C_{R} S\left(T_{g}^{4}-T_{r t}^{4}\right) \\
\dot{Q}_{f} \approx C_{R} S T_{g}^{4} \leftrightarrow T_{r t} \rightarrow 0 \\
\dot{m}_{f b}=\dot{m}_{f}\left(1-e^{\frac{\tau}{T_{f}}}\right)
\end{gathered}
$$

With the conservation of mass, this is the equation resulting from equation (1)

$$
V_{f} \frac{d \rho_{g}}{d t}=\dot{m}_{a}+\dot{m}_{f b}-\dot{m}_{g}
$$

with $m_{g}=k_{f} P_{f}$, where $k_{f}$ is the friction coefficient, $P_{f}$ is the pressure inside the furnace.

$$
\dot{m}_{a}=V_{f} \frac{d \rho_{g}}{d t}-\dot{m}_{f b}-\dot{m}_{g}
$$

Inserting (4) in (5) yields 
International Journal of Advances in Scientific Research and Engineering (ijasre), Vol 6 (9), September -2020

$$
\begin{array}{r}
\dot{m}_{a}=V_{f} \frac{d \rho_{g}}{d t}-\dot{m}_{f}\left(1-e^{\frac{\tau}{T_{f}}}\right)-\dot{m}_{g} \\
\frac{\dot{m}_{a}}{\dot{m}_{f}}=\frac{V_{f}}{\dot{m}_{f}} \frac{d \rho_{g}}{d t}-\left(1-e^{\frac{\tau}{T_{f}}}\right)-\frac{\dot{m}_{g}}{\dot{m}_{f}} \\
A \dot{F} R=\frac{V_{f}}{\dot{m}_{f}} \frac{d \rho_{g}}{d t}-\left(1-e^{\frac{\tau}{T_{f}}}\right)-\frac{\dot{m}_{g}}{\dot{m}_{f}}
\end{array}
$$

Equation (4) shows that maximum mass burned, $\left(m_{f b}\right.$ tends to $\left.m_{f}\right)$, if $T_{f}$ tends to the characteristic time constant $\tau$.

\subsection{Analysis of the data collected from the site}

The model is to be validated by comparing measure values with computed using equation (6). and doing that for different plants. Data from Jabana II Oil Thermal Power Plant have been used. The density of the gas and the temperature of the fuel at unlet have been used to compute the Air Fuel Ratio keeping all other parameters in equation (6) constant. $\frac{V_{f}}{\dot{m}_{f}}$ which is the inverse of the density of the fuel at the beginning is kept to $2 \mathrm{~m}^{3} / \mathrm{kg}, T_{f}=30^{\circ} \mathrm{C}$ and $\tau$ close to $T_{f}=23$.

The results are shown in the figures.
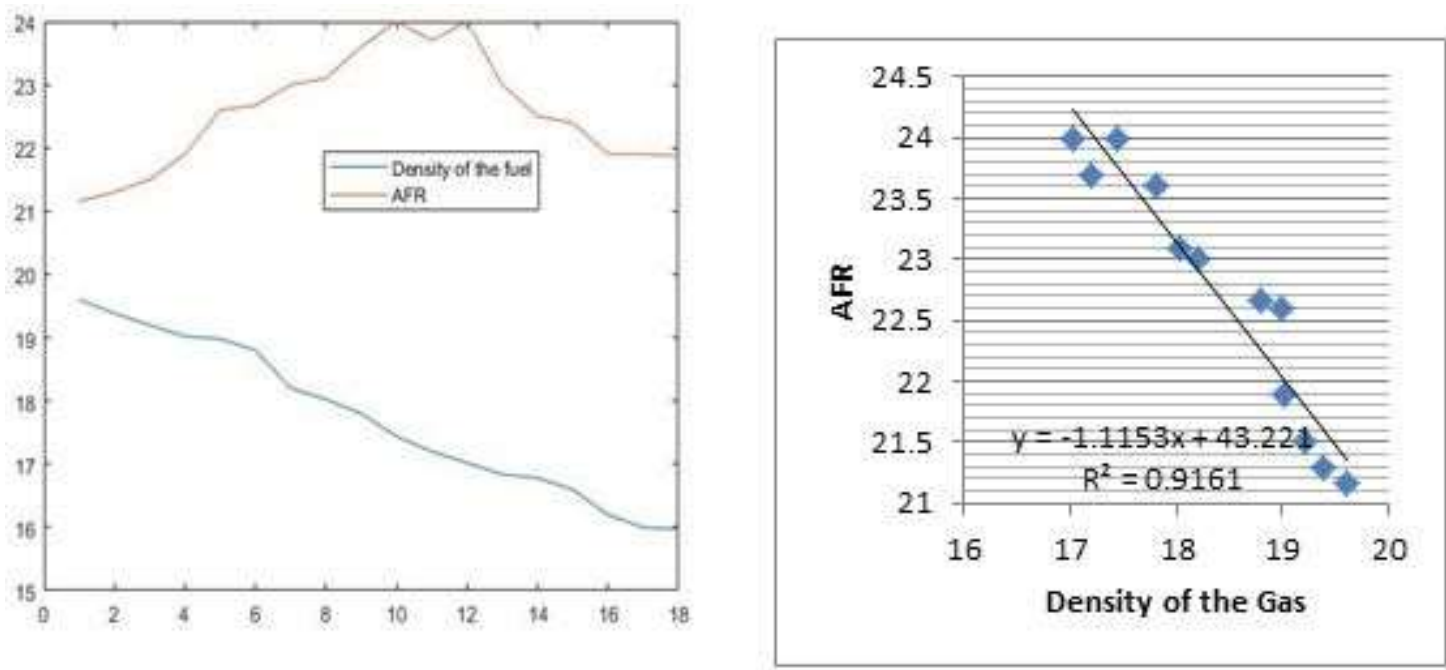

Figure 2: Variation of the Air Fuel Ratio and the Density of the Gas
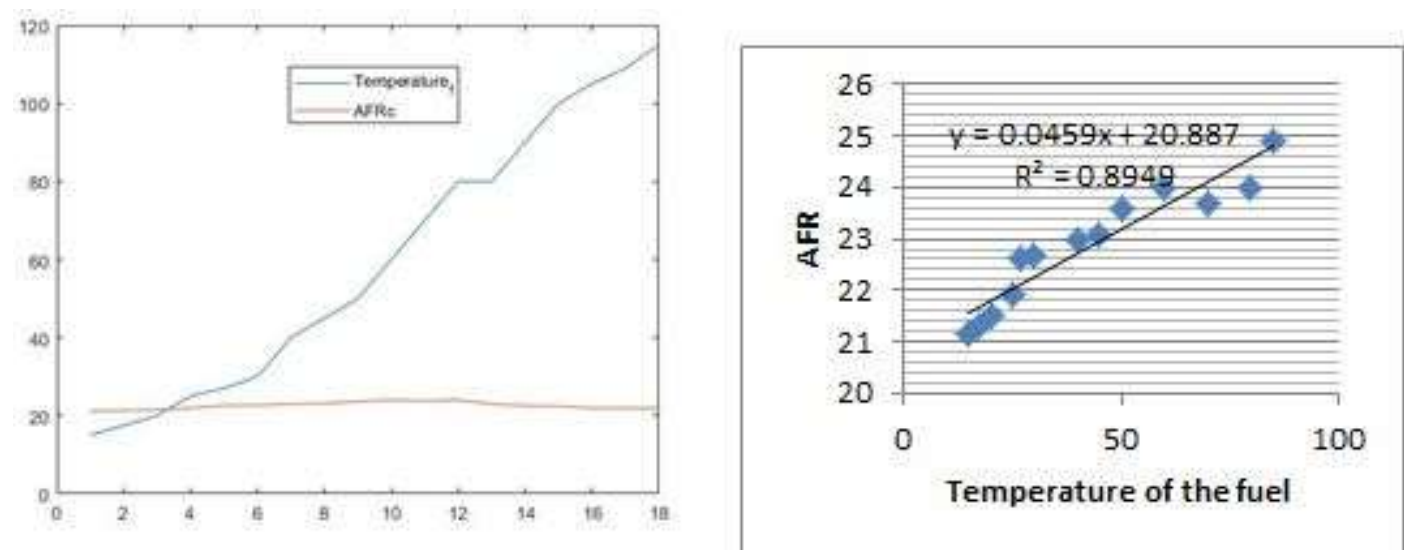

Figure 3: Variation of the Air Fuel Ratio with the temperature of the fuel

Error! Reference source not found. shows how the AFR is inversely proportional to the density and Error! Reference source not found. shows that the increase of the temperature causes increase of the AFR, however this change has a limit for both the density and the temperature. 
International Journal of Advances in Scientific Research and Engineering (ijasre), Vol 6 (9), September -2020
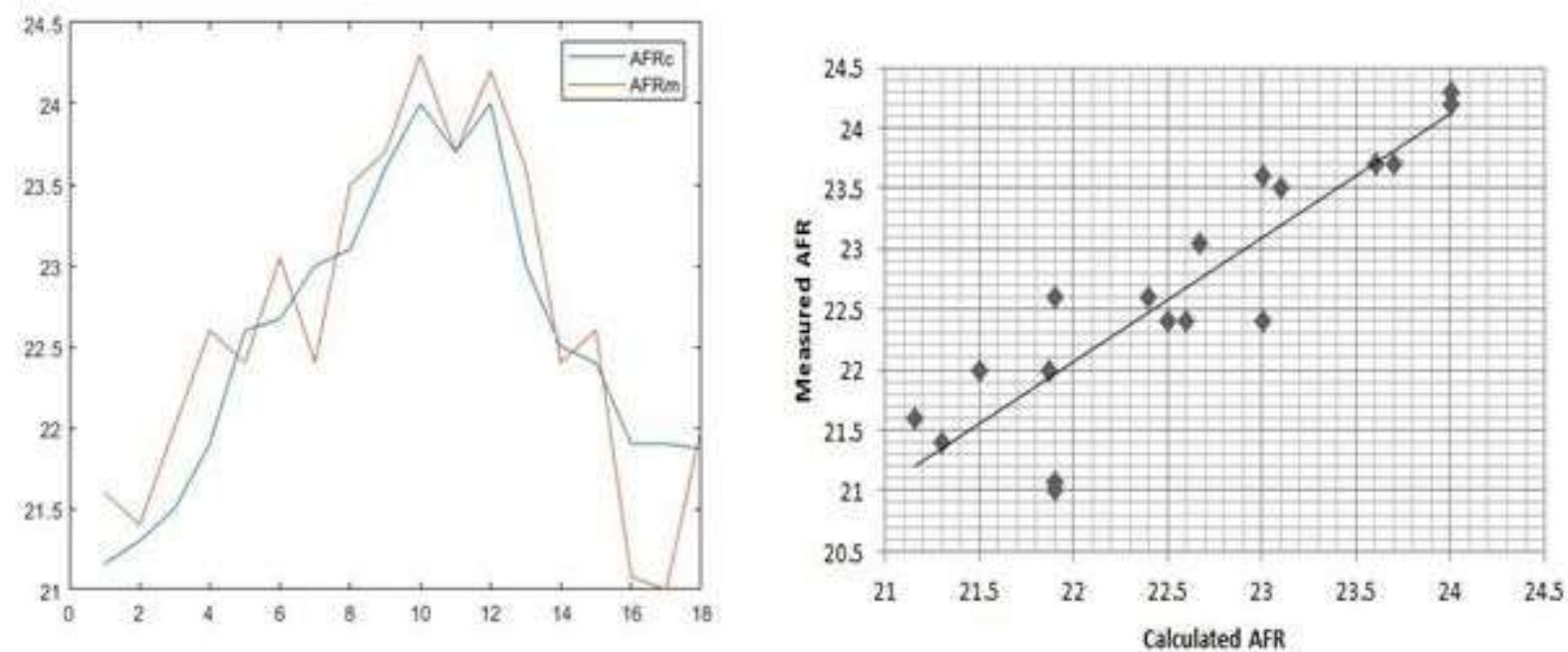

Figure 4: Comparison of measured and Calculated AFR

Error! Reference source not found. shows that values found by calculating by using the demonstrated equation (6) and the value of the AFR measured are close.

\section{CONSIDERATION OF THE PRESSURE}

\subsection{Formulation of the model}

This is based on the physical principle of conservation of momentum and mass

Variation of the pressure is proportional to the mass variation [14]

$$
\frac{d P}{d t}=\frac{r}{V} \cdot T \cdot \frac{1}{\mu} \cdot \frac{d M}{d t}
$$

With the assumption that the internal pressure of the furnace somewhat close to the atmospheric pressure (case of perfect/idea gasses); where $r, \mathrm{~V}, \mathrm{~T}, \mathrm{M}, \mu$, P represent respectively, the constant of a perfect gas, Volume, Temperature, Mass, molecular mass and Pressure.

The airflow $C_{a}$ is the sum of the flow of the oxygen $C_{\mathrm{O}_{2}}$ and the nitrogen $C_{N_{2}}$ :

$$
C_{a}=C_{O_{2}}+C_{N_{2}}
$$

$\left\{\begin{array}{l}C_{O_{2}}=m_{O_{2}} C_{a} \\ C_{N_{2}}=m_{N_{2}} C_{a}\end{array}, m_{O_{2}}\right.$ : the mixture of oxygen and $m_{N_{2}}$ : the mixture of nitrogen.

The quantity of the oxygen and nitrogen flow with time depends also on the percentage in the air; so

$\frac{1}{\mu} \frac{d M}{d t}=k_{a} C_{a}$ for $k_{a}=\frac{m_{O_{2}}}{\mu_{O_{2}}}+\frac{m_{N_{2}}}{\mu_{N_{2}}}$

On another hand, the coal or fuel flow in use consists of a mixture of carbon, hydrogen, sulfur, nitrogen, and oxygen (from water vapor) in different percentages. The combustion of each of the element of the air produces $\mathrm{CO}_{2}, \mathrm{H}_{2} \mathrm{O}, \mathrm{SO}_{2}$, and $\mathrm{NO}_{2}$. For the case of Oxygen, it is negative, since it is present in the air but it doesn't undergo the combustion process.

This yields the following

$$
\frac{1}{\mu} \frac{d M}{d t}=k_{c} C_{c} \text { for } k_{c}=\frac{m_{C_{2}}}{\mu_{C O_{2}}}+\frac{m_{\mathrm{NO}_{2}}}{\mu_{\mathrm{NO}_{2}}}+\frac{m_{\mathrm{SO}_{2}}}{\mu_{\mathrm{SO}_{2}}}+\frac{m_{\mathrm{H}_{2} \mathrm{O}}}{\mu_{\mathrm{H}_{2} \mathrm{O}}}-\frac{m_{\mathrm{O}_{2}}}{\mu_{\mathrm{O}_{2}}}
$$

Using the variation of total mass within the furnace by the fact that both air and the fuel enter but the exhaust $C_{e}$ exit, the following expression will result. 
International Journal of Advances in Scientific Research and Engineering (ijasre), Vol 6 (9), September -2020

$$
\frac{1}{\mu} \frac{d M}{d t}=k_{c} C_{c}+k_{a} C_{a}-k_{e} C_{e}
$$

A combination of (7) and (8) gives

$$
\begin{gathered}
\frac{d P}{d t}=\frac{r}{V} T\left(k_{c} C_{c}+k_{a} C_{a}-k_{e} C_{e}\right) \\
\frac{1}{C_{c}} \frac{d P}{d t}=\frac{r}{V} T\left(k_{c}+k_{a} A F R-k_{e} \frac{C_{e}}{C_{c}}\right) \\
\frac{1}{C_{c}} \frac{d P}{d t}=k A F R+k k_{c}-k k_{e} \frac{C_{e}}{C_{c}} \text { for } k=\frac{r}{V} T
\end{gathered}
$$

Finally, the resulting model is found as follows.

$$
A F R=\frac{1}{k C_{c}} \frac{d P}{d t}+k_{c}-k_{e} \frac{C_{e}}{C_{c}}
$$

\subsection{The use of the data from the site/JabanaII Oil Power Plant}
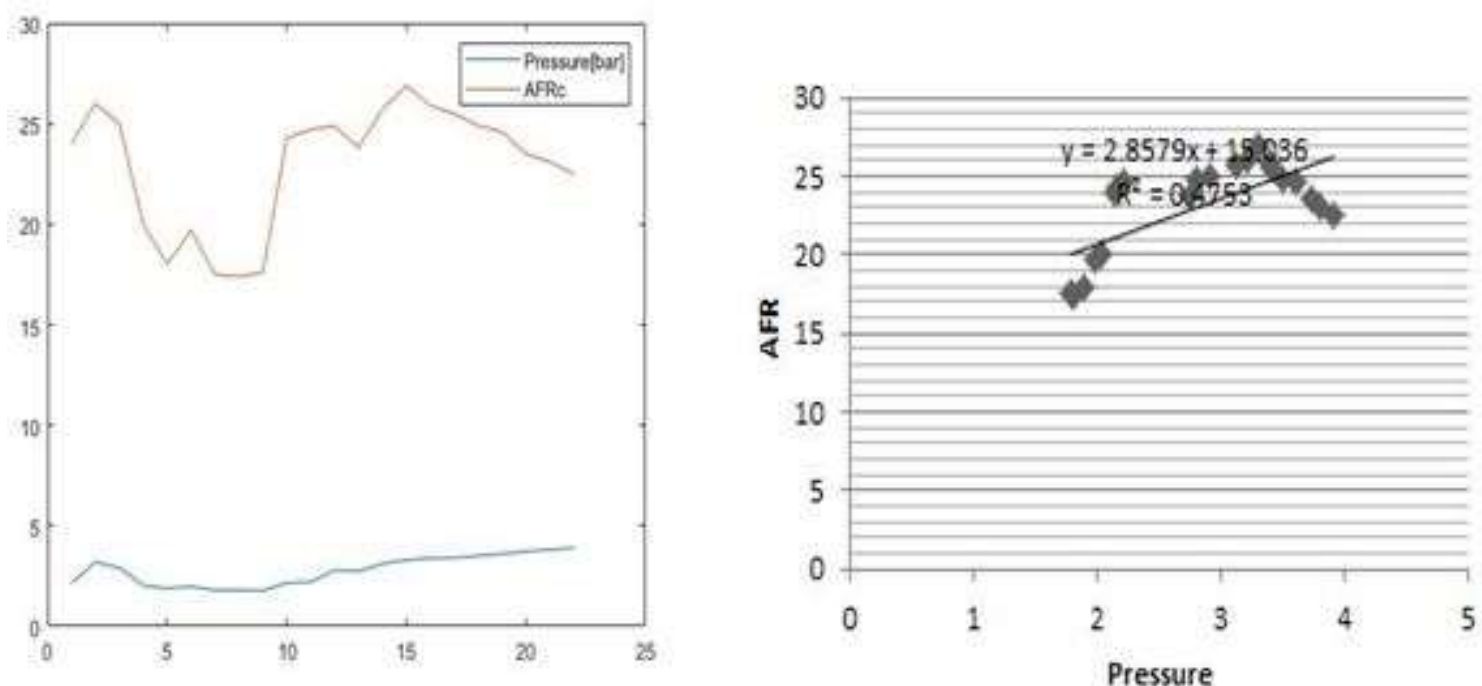

Figure 5: Variation of the AFR with the pressure of the fuel at unlet

Error! Reference source not found. shows that the increase of the pressure and the temperature causes an increase in the air-fuel ratio but it starts to decrease when the pressure becomes higher.
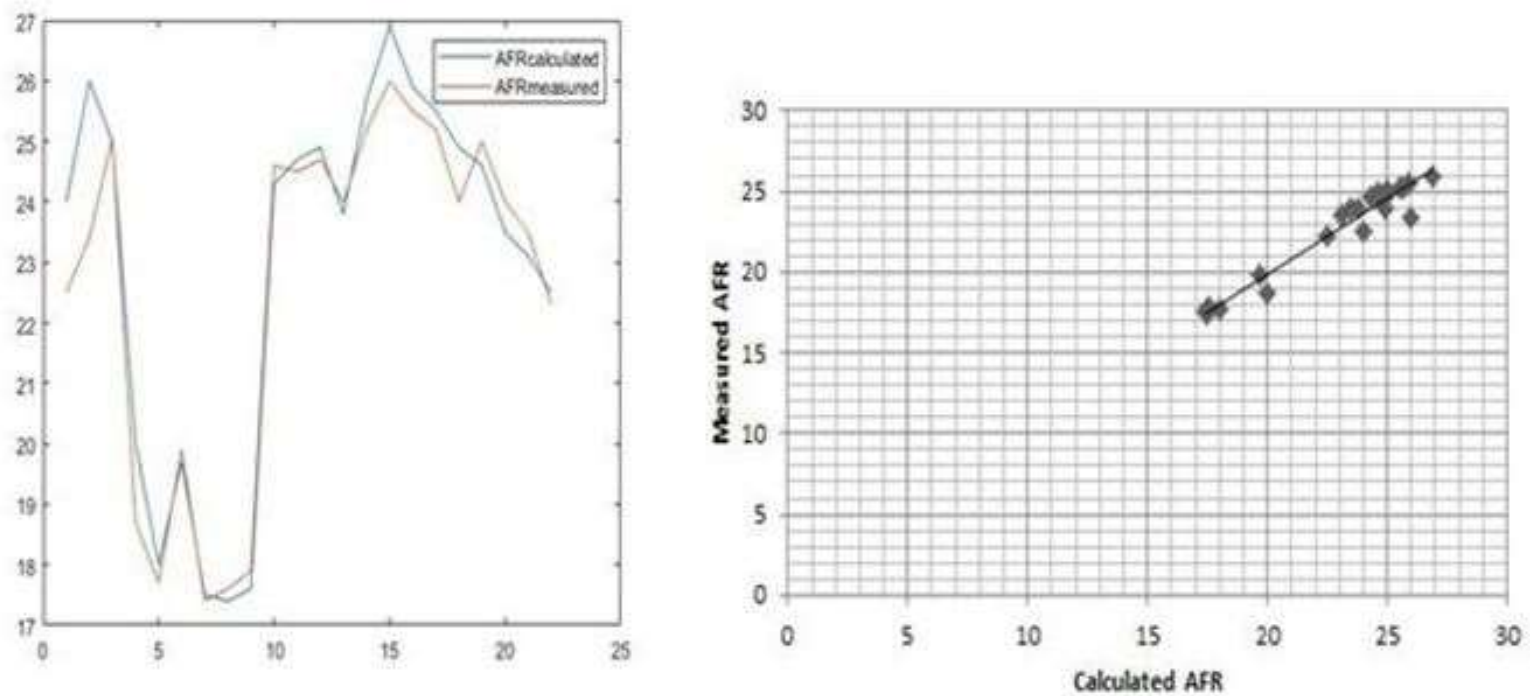

Figure 6: Comparison of Measured and Calculated AFR 
Error! Reference source not found. shows that values found by calculating by using the demonstrated equation (Error! Reference source not found.) and the value of the AFR measured are close.

\section{CONCLUSION}

The increase of the temperature and reduction of the density of the air make the AFR high before it reaches the values at which it starts to be small. Thus, it can take the stoichiometric value to a lean state. It is an advantage in the sense that all the fuel will be burned. On another hand, it causes the high nitrogen composition in the exhaust which is negative for the combustion efficiency and the successful performance of the boiler. Consideration of the efficiency of the boiler/combustion to optimize the parameters for different working fluid of the plant gives the setting of the AFR. Once this is found, the variation of the density, pressure, and temperature could be done meeting the AFR that has to be achieved. Next, there will be an investigation of what is the better AFR for the cases of thermal power in Rwanda, and build the control method that would stabilize independent variables.

\section{REFERENCES}

[1] R. Pradhan, P. Ramkumar, and M. Sreenivasan, "Air-Fuel Ratio ( Afr ) Calculations In An Internal Combustion Engine Based On The Cylinder Pressure Measurements,” Int. J. Eng. Res. Apllication, vol. 2, no. 6, pp. 1378-1385, 2012.

[2] B. Abbas Al-Himyari, A. Yasin, and H. Gitano, "Review of Air-Fuel Ratio Prediction and Control Methods," Asian J. Appl. Sci., vol. 2, no. 4, pp. 471-478, 2014.

[3] A. Marjanovi, "Control of Thermal Power Plant Combustion Distribution Using Extremum Seeking,” vol. 25, no. 5, pp. $1670-1682,2017$.

[4] S. Mcallister, Thermodynamics of Combustion, no. April. 2014.

[5] A. H. Al-abbas and J. Naser, "CFD Modelling of Air-Fired and Oxy-Fuel Combustion in a 100 kW Unit Firing Propane ICME11-TH-004 CFD MODELLING OF AIR-FIRED AND OXY-FUEL COMBUSTION IN A 100 KW UNIT FIRING PROPANE," no. August 2017, 2011.

[6] G. A. Richards, “A Model for Premixed Combustion Oscillations Technical Note,” vol. 1026, no. 304, pp. 1-28, 1996.

[7] E. H. R. Janus, M.C, G.A. Richards, M.J. Yip, "Effects of Ambient Conditions and Fuel Composition on Combustion Stability,” 1997 Am. Soc. Mech. Eng. (ASME)/International Gas Turbine Inst. Turbo Expo Meet., 1997.

[8] H. F. Alajmi, "Effect of Ambient Air Temperature on the Performance of Steam Generator," vol. 8, no. 7, pp. 479-483, 2017.

[9] L. Chao, L. Ke, W. Yongzhen, M. Zhitong, and G. Yulie, “The Effect Analysis of Thermal Efficiency and Optimal Design for Boiler System,” Energy Procedia, vol. 105, pp. 3045-3050, 2017.

[10] C. Principles, “A Boiler Combustion Control System with Combustion Ratio Optimisation and Soft Measurements," vol. 43, no. May, pp. 112-115, 2010.

[11] M. N. Bera, A. Riera, and M. Lewenstein, "Universal Laws of Thermodynamics,” no. December, 2016.

[12] Introduction to Modeling and Control of Internal Combustion Engine Systems, Springer, 1395.

[13] F. P. Ion V. Ion, "Dynamic model of a steam boiler furnace,” no. February, 2019.

[14] A. O. S. R. G. Freire, J. M. Lemos, "MODELLING THE AIR/FLUE-GAS CIRCUIT OF A THERMOELECTRIC POWER PLANT UNIT." 